\title{
STUDY OF RADIAL-SHEAR ROLLING FEATURES AND PROPERTIES EVOLUTION OF 1050A ALUMINUM ALLOY
}

\author{
Yury GAMIN, Alexander KOSHMIN, Alexander DOLBACHEV \\ National University of Science and Technology «MISIS», Moscow, Russian Federation, \\ gamin910@gmail.com
}

https://doi.org/10.37904/metal.2020.3467

\begin{abstract}
The main goal of this study is to analyze the influence of radial-shear rolling (RSR) modes on the structure and properties of 1050A using finite element modeling (FEM) and experimental verification of the results. Ingots with a diameter of $60 \mathrm{~mm}$ were obtained, which were rolled into rods with a diameter of $14 \mathrm{~mm}$ at different regimes (total elongation ratio $\mu=18.4$ ). After rolling, the evolution of the microstructure and mechanical properties of the resulting rods were investigated. It is established that during RSR process the nonuniform change in temperature-velocity and deformation parameters occurs in the volume of deformable body, which determines the forming of gradient spiral structure. FEM was used for good understanding processes of microstructure evolution and properties depending on parameters of RSR methods. Based on the FEM simulation the change in temperature and strain rates in the volume of deformed body at different temperature ( $\mathrm{T}=25$ up to $350^{\circ} \mathrm{C}$ ) was obtained. Depending on the selected temperature-velocity parameters it is possible to obtain a different combination of mechanical properties (UTS $~ 94$ up to $20 \mathrm{MPa}$; YS $~ 88$ up to $110 \mathrm{MPa}$; $\mathrm{e}=1$ up to $43.5 \%$ ). The strength of obtained RSR rods from 1050A alloy at all regimes is significantly higher than the strength of industrial rods in a hot-pressed condition that shows the application prospect of RSR process as efficient method of controlled plastic deformation of aluminum alloys and obtaining long rods.
\end{abstract}

Keywords: Aluminum alloys, radial-shear rolling, finite element modeling, plastic deformation, feed angle, elongation ratio, deformation regime.

\section{INTRODUCTION}

The production of semi-finished products from aluminum alloys is an important component of the metallurgy and engineering industries. The semi-finished products in the form of long rods are widely used as the constructional material for production of parts and equipment in the aircraft and automotive industries, etc. $[1,2]$.

Now the works on creation of fundamentally new types of materials with unique set of properties $[3,4]$ or improving materials properties with new processing methods in particular severe plastic deformation (SPD) [5-7] are one of the high-demand directions in the field of materials research. Currently, a lot of SPD methods have been developed and studied in sufficient detail as applied to various metals and alloys. Good results are shown for the method of equal channel angular pressing (ECAP) as applied to aluminum [8], copper [9] and other alloys. Also, quite a number of investigations is devoted to methods of high pressure torsion (HPC) [10, 11]. At the same time, the industrial application of these methods and obtaining products with a high level of properties and sufficiently large sizes (lengths) remains an urgent issue. This article describes the method of radial-shear rolling (RSR), which allows obtaining long rods from a wide range of steels and alloys of nonferrous and ferrous metals [12-15]. Due to shear deformations arising during rolling the complicated spiral structure is formed in the workpiece volume and the working of material and decrease in grain size are occurred [16]. Thus, in the deformation zone under the action of work rolls of special calibration the conditions close to 
SPD and contributing to increasing of properties level of semi-finished products can be realized. This processing method has found application in technologies for producing precision rods from titanium alloys and various alloyed steels $[17,18]$. For aluminum alloys the pressing is main method for the production of semifinished products in the form of rods, therefore, it is relevant to study the RSR features of aluminum-based alloys in order to create an industrial technology for producing rods with a high level of mechanical properties. The published results of experimental studies [19-21] show the promising of this method as applied to aluminum alloys, however, a more detailed study of regimes and deformation conditions are required, which will formulate the basic principles for the technology. This article proposes to use the FEM modeling for this, which makes possible to determine the main temperature, velocity, and deformation parameters affecting the structure and properties formation of material.

The main goal of this study is to analyze the influence of radial-shear rolling (RSR) regimes on the structure and properties of $1050 \mathrm{~A}$ using finite element modeling (FEM) and experimental verification of the results.

\section{EXPERIMENTAL METHODS}

Experimental studies were carried out on 1050A industrial aluminum alloy (standard EN $573-3$ Ingots with a diameter of $60 \mathrm{~mm}$ and a length of $230 \mathrm{~mm}$ used as initial workpiece for rolling were rolled in 5 passes to final diameter of $14 \mathrm{~mm}$ according with reductions presented in Table 1.

Table 1 Deformational conditions of rolling

\begin{tabular}{|c|c|c|c|c|}
\hline Pass Number, $\mathbf{i}$ & $\begin{array}{c}\text { Diameter of workpiece } \mathbf{D}_{\mathbf{i}-1}, \\
\mathbf{m m}\end{array}$ & $\begin{array}{c}\text { Diameter of the resulting } \\
\text { rod } \mathbf{D}_{\mathbf{i}}, \mathbf{m m}\end{array}$ & $\begin{array}{c}\text { Elongation ratio } \\
\boldsymbol{\mu}_{\mathbf{i}}\end{array}$ & $\boldsymbol{\Sigma}_{\boldsymbol{i}}$ \\
\hline 1 & 60 & 42 & 2.04 & 2.04 \\
\hline 2 & 42 & 31 & 1.84 & 3.75 \\
\hline 3 & 31 & 24 & 1,67 & 6.25 \\
\hline 4 & 24 & 17 & 1.99 & 12.46 \\
\hline 5 & 17 & 14 & 1.47 & 18.37 \\
\hline
\end{tabular}

The heating temperature of workpieces before deformation $T_{0}$ is the main varied parameter during the study. The values of $\mathrm{T}_{0}=25,200,250,300$ and $350{ }^{\circ} \mathrm{C}$ were chosen corresponding to cold, warm and hot deformation. The initial workpiece was heated in chamber electric-heating furnace before rolling. After each pass the rod was returned to furnace for temperature equalization.

The work rolls of RSR-minimill turned at feed angle of $20^{\circ}$ rotate in one direction and have the reduction and calibration zones of workpiece where regular round rod profile is formed.

After rolling the mechanical properties of rods with diameter of $14 \mathrm{~mm}$ were determined without previous preparation by Zwick 250 test machine. The samples testing was carried out at ambient temperature with strain rate of $10 \mathrm{~mm} / \mathrm{min}$. Electron backscatter diffraction (EBSD) microstructure analysis was also conducted by using a field emission scanning electron microscope TESCAN VEGA LMH. The EBSD analysis of the alloy was performed using a NordlysMax2 detector (Oxford Instruments Advanced AZtecEnergy). Polished samples were used for the studies.

The computer simulation of RSR process was performed in QFORM program (LLC "QuantorForm", Russia) according to the modes presented in the Table 1. During the simulation, the following main model parameters were adopted: the friction factor is 0.93 , the tool temperature is $25^{\circ} \mathrm{C}$, the rotary velocity of the work rolls is 30 rpm, and the ambient temperature is $20^{\circ} \mathrm{C}$. 


\section{RESULTS AND DISCUSSION}

\subsection{FEM simulation}

To estimate the temperature change after rolling depending on heat temperature $T_{0}$ and rod diameter the temperature graph after each pass was constructed (Figure 1). For this purpose, three control points located on workpiece surface (P1), at a distance of $1 / 2$ radius (P2) and on the workpiece axis (P3) were chosen. At these points the temperature readings were taken at each step of calculation along their movement trajectory. The temperature after rolling was determined as the average value at three control points.

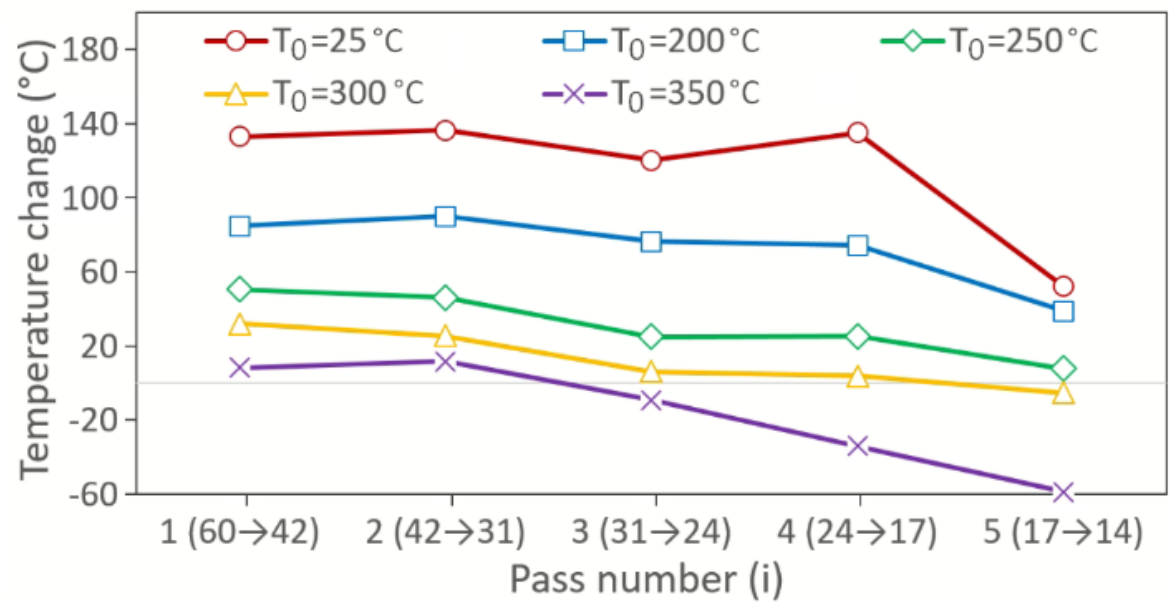

Figure 1 The graphs of temperature change after each pass

The data obtained show that temperature change of rod with account for deformation heating and heat exchange with tool and environment. With increasing in heat temperature of rods the temperature change after each pass is reduced. This tendency is due to increase the difference between workpiece temperature and work tool. During the rolling process the workpiece comes into contact with cold rolls for a long time as a result of which its surface is cooled. With each following pass the effect of temperature heating decreased since the diameter of rod reduces and its length increases.

As can be seen from the graph the greatest heating of rods is observed for $\mathrm{T}_{0}=25^{\circ} \mathrm{C}$ and reaches $140{ }^{\circ} \mathrm{C}$. The onset temperature of recrystallization for $1050 \mathrm{~A}$ alloy is $290^{\circ} \mathrm{C}$ due to this the probability of recrystallization for $\mathrm{T} 0=25$ until $200^{\circ} \mathrm{C}$ is low It can be predictable that partially crystallized and predominantly crystallized structures will be observed at $\mathrm{T}_{0}=250$ until $300{ }^{\circ} \mathrm{C}$, and at heating to $350{ }^{\circ} \mathrm{C}$, respectively. To verify that assumption the analysis of microstructure and mechanical properties was carried out in this study.

\subsection{Microstructure}

EBSD analysis was carried out for the rod with diameter of $14 \mathrm{~mm}$ deformed at temperature of $250{ }^{\circ} \mathrm{C}$. The maps of grain orientation for three control zones such as center, half of radius and surface are presented in Figure 3.

As it can be seen, the central zone of workpiece consists of deformed grains elongated along rolling axis. The average grain size is $19.9 \mu \mathrm{m}$. The road surface has predominantly recrystallized structure with a small fraction of ultrafine-grained deformed grains with an average diameter of $4 \mu \mathrm{m}$. The transition zone of rod cross-section is the combination of two above-describe structures: partly deformed and recrystallized ones. Obviously, in this zone the average grain size $(\mathrm{d} \sim 13 \mu \mathrm{m})$ is in the size range of grains in the center and on the surface. The obtained maps of size distribution and grain orientation after RSR are in good agreement with data from $[16,19,20]$ and results of simulation in QFORM 3D. 

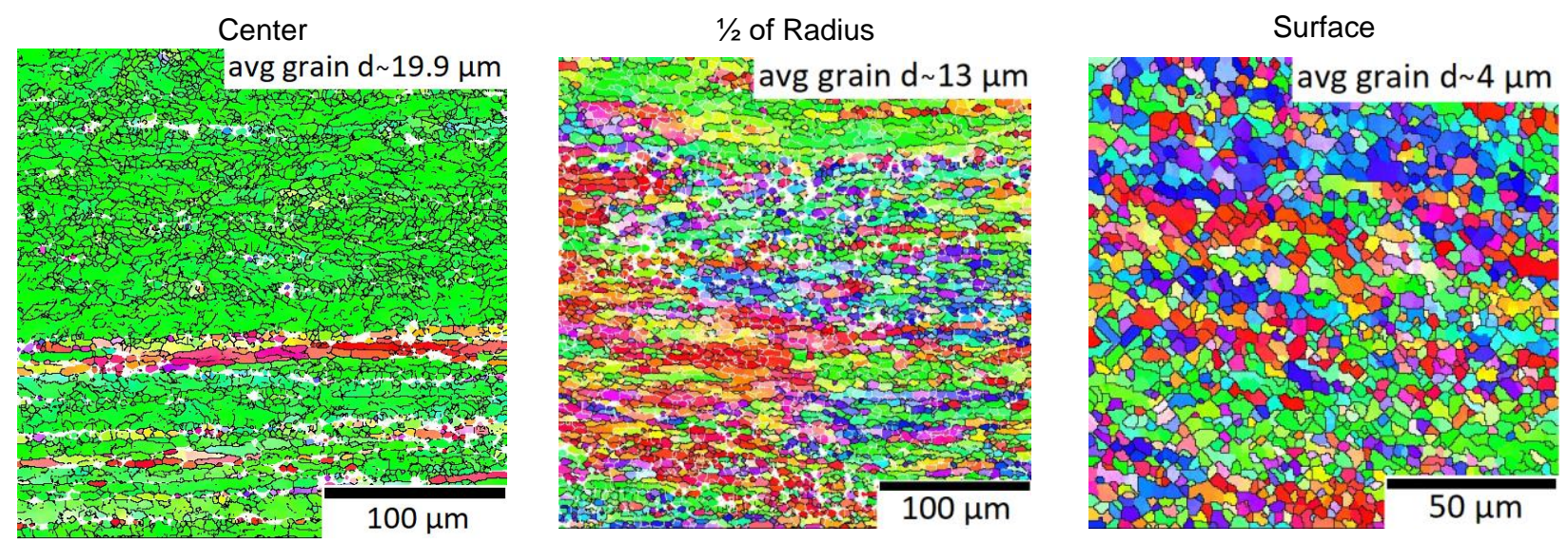

Figure 3 EBSD micrograph (colour map) of grain orientation for $1050 \mathrm{~A}$ alloy rod with $\mathrm{D}_{5}=14 \mathrm{~mm}\left(\mathrm{~T}_{0}=250{ }^{\circ} \mathrm{C}\right.$; longitudinal section)

\subsection{Mechanical properties}

The mechanical properties of rods with diameter of $14 \mathrm{~mm}$ obtained by RSR method at different heating temperatures are presented in Figure 4. The rods with the heating temperature of 25 until $200^{\circ} \mathrm{C}$ before rolling have high strength UTS $\sim 114.7$ until $121.7 \mathrm{MPa}$ and low ductility $\mathrm{e} \sim 1 \%$, that is corresponds to cold rolling conditions. Beginning from the temperature of $250^{\circ} \mathrm{C}$ there are slightly decrease in strength properties of rods and increase in plastic ones.

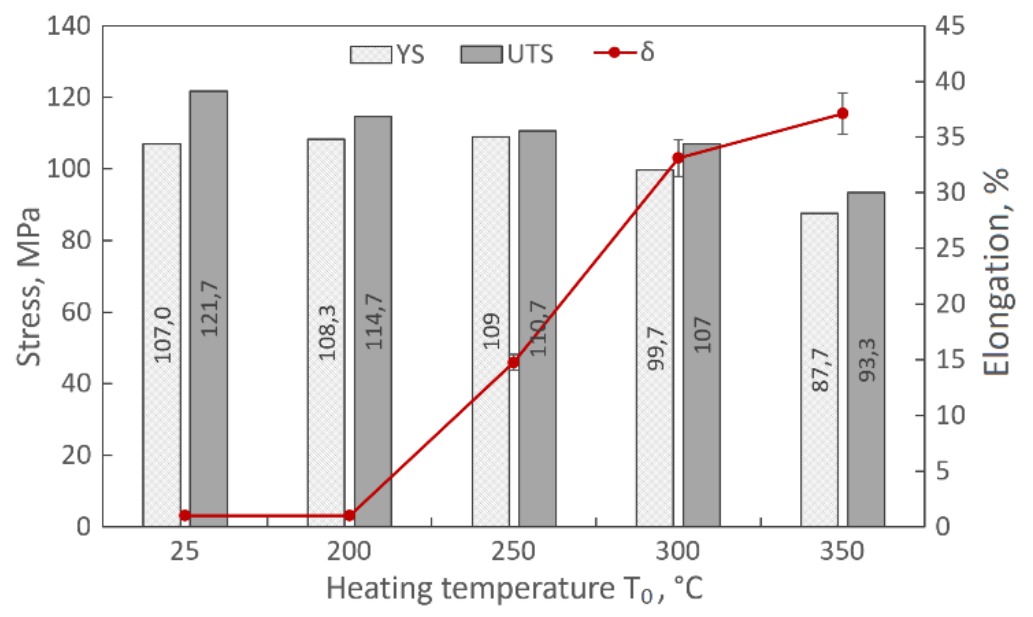

Figure 4 The mechanical properties of 1050A alloy after RSR at different temperatures.

According to the obtained results it can be indirectly judged the fraction distribution of recrystallized and deformed structures. It can be seen that a heating temperature of $200{ }^{\circ} \mathrm{C}$ is not enough to start the recrystallization process in $1050 \mathrm{~A}$ alloy. At temperature of $250^{\circ} \mathrm{C}$, the partly recrystallized structure is obtained, where the fine recrystallized grain from the surface is gradually replaced by deformed structure in the center of rod that is confirmed by the data obtained after EBSD analysis (Figure 3). Such structure provides the high strength properties and maintenance of plastic ones that is necessary for structural materials. A further temperature rise of deformation increases fraction of recrystallized structure and leads to decrease in strength.

\section{CONCLUSION}

The article discussed the features of structure and properties formation of $1050 \mathrm{~A}$ aluminum alloy during RSR process. 
Based on FEM results the analysis of temperature change during RSR process in depending on initial heating temperature and reduction per pass was carried out. The deformation heating of rod during the deformation process is the greater than the initial temperature of workpiece is lower. The largest temperature amplitude is observed on the workpiece surface where the deformation is localized and the periodic contact with work rolls occurs.

The deformation temperature can be considered as the main parameter for control of structure formation during RSR process. As analysis shows, it is possible to obtain required fraction ratio of deformed and recrystallized structures by setting temperature-deformation parameters, and thus, to control the level of mechanical properties.

The obtained data can be used for principles formation of industrial method for controlled deformation of semifinished products from aluminum alloys with a given structure and properties.

\section{ACKNOWLEDGEMENTS}

The research was supported by Russian Science Foundation (project No. 19-79-00054).

\section{REFERENCES}

[1] TOTTEN, G. E., MACKENZIE, D. S. Handbook of aluminium. Vol. 1. Physical metallurgy and processes. New York: CRC Press, Marcel Dekker Inc., 2003.

[2] WILLIAMS, J. C., STARKE, E. A. Progress in structural materials for aerospace systems. Acta Materialia.2003, vol.51, no. 19, pp. $5775-5799$.

[3] ZHANG, P., YUAN, Y., GU, Y.F., YAN, J.B., DANG, Y.Y., LU, J. T., WANG, J.C. Investigation on the tensile deformation mechanisms in a new Ni-Fe-base superalloy HT700T at $750{ }^{\circ} \mathrm{C}$, Journal of Alloys and Compounds. 2020, vol. 825., 154012.

[4] AKOPYAN, T. K., BELOV, N. A., NAUMOVA, E. A., LETYAGIN, N. V. New in-situ al matrix composites based on Al-Ni-La eutectic. Materials Letters. 2019, vol. 245, pp. 110-113.

[5] KLIAUGA, A.M., SORDI, V.L., DE VINCENTIS, N.S., et al. Severe Plastic Deformation by Equal Channel Angular Pressing and Rolling. The Influence of the Deformation Path on Strain Distribution. Advanced Engineering Materials. 2018, vol. 20, no. 4, 1700055.

[6] ARIVU, M., HOFFMAN, A., DUAN, J., WEN, H., ISLAMGALIEV, R., VALIEV, R. Severe plastic deformation assisted carbide precipitation in Fe-21Cr-5Al alloy. Materials Letters.2019, vol. 253, pp. 78-81.

[7] QI, Y., KOSINOVA, A., KILMAMETOV, A. R., STRAUMAL, B. B., RABKIN, E. Stabilization of ultrafine-grained microstructure in high-purity copper by gas-filled pores produced by severe plastic deformation. Scripta Materialia. 2020, vol.178, pp. 29-33.

[8] VERLINDEN, B., CHEN, E., DUCHÊNE, L., et al. Transient Yielding during Compression Tests on ECAP'ed AA1050 Aluminium. Materials Science Forum.2011, vol. 667-669, pp. 955-960.

[9] KLIAUGA, A.M., SORDI, V.L., DE VINCENTIS, N.S., et al. Severe Plastic Deformation by Equal Channel Angular Pressing and Rolling: The Influence of the Deformation Path on Strain Distribution. Advanced Engineering Materials. 2018, vol.20, no.4, 1700055.

[10] VERLEYSEN, P., LANJEWAR, H. Dynamic high pressure torsion: A novel technique for dynamic severe plastic deformation. Journal of Materials Processing Technology.2020, vol. 276, 116393.

[11] DEGTYAREV, M.V., PILYUGIN, V.P., CHASHCHUKHINA, T.I. et al. Structure of Iron Deformed at $250^{\circ} \mathrm{C}$ by Torsion under a Pressure. Physics of Metals and Metallography.2019, vol.120, pp. 1193-1199.

[12] GALKIN, S.P., ROMANTSEV, B.A., GAMIN, YU. Resource-saving technology for production of round bars from used shaft of rolling railroad stock. Chernye Metally.2018, no. 4, pp. 20-27.

[13] MALAKHOV, YU., SAIKOV, A., I., DENISOV, I. V., CHEREZOV, N. P., GAMIN, Y. V., ROMANTSEV, B. A. Obtaining two-layered pipes and rods using explosion energy and hot deformation. Journal of Physics:

Conference Series.2020, vol. 1431, iss.1, 012033. 
[14] NEGODIN, D.A., GALKIN, S.P., KHARITONOV, E.A. et al. Testing of the Technology of Radial-Shear Rolling and Predesigning Selection of Rolling Minimills for the Adaptable Production of Titanium Rods with Small Cross Sections Under the Conditions of the "CHMP" JSC. Metallurgist.2019, vol. 62, pp. 1133-1143.

[15] GALKIN, S. P., GONCHARUK, A. V., DAEVA, E. K., MIKHAILOV, V. K., ROMANTSEV, B. A. Multipass screwrolling system. Steel in Translation, 2003, 33, no. 9, pp. 45-47.

[16] DOBATKIN, S., GALKIN, S., ESTRIN, Y., et al. Grain refinement, texture, and mechanical properties of a magnesium alloy after radial-shear rolling. Journal of Alloys and Compounds.2019, vol. 774, pp. 969-979.

[17] ROMANCEV, B.A., GONCHARUK, A.V., ALESHCHENKO, A.S., GAMIN, Y.V. Production of hollow thick-walled profiles and pipes made of titanium alloys by screw rolling. Russian Journal of Non-Ferrous Metals.2015, vol.56, no.5, pp. 522-526.

[18] SKRIPALENKO, M.M., ROMANTSEV, B.A., KAPUTKINA, L.M. et al. Study of Transient and Steady-State Stages During Two-High and Three-High Screw Rolling of a 12Kh18N10T Steel Workpiece. Metallurgist.2019, vol.63, pp. 366-375.

[19] AKOPYAN, T.K., ALESHCHENKO, A.S., BELOV, N.A., GALKIN, S.P. Effect of Radial-Shear Rolling on the Formation of Structure and Mechanical Properties of Al-Ni and Al-Ca Aluminum-Matrix Composite Alloys of Eutectic Type. Physics of Metals and Metallography.2018, vol.119, no. 3, pp. 241-250.

[20] AKOPYAN, T.K., BELOV, N.A., ALESHCHENKO, A.S. et al. Formation of the gradient microstructure of a new Al alloy based on the Al-Zn-Mg-Fe-Ni system processed by radial-shear rolling. Materials Science and Engineering A. 2019, vol. 746, pp. 134-144.

[21] VALEEV, I.S., VALEEVA, A.K., FAZLYAKHMETOV, R.F. et al. Effect of radial-shear rolling on structure of aluminum alloy D16 (Al-4.4Cu-1.6Mg). Inorganic Materials: Applied Research.2015, no.6, pp. 45-48. 